\title{
A case of Salmonella typhi neonatal meningitis
}

\author{
*Imalke Kankananarachchi ${ }^{1}$, Thilina Madushanka ${ }^{2}$, Chamidri Naotunna ${ }^{2}$, Bhagya Piyasiri ${ }^{2}$, \\ I V Devasiri ${ }^{1}$
}

Sri Lanka Journal of Child Health, 2019; 48(4): 350-352

DOI: http://dx.doi.org/10.4038/sljch.v48i4.8833

(Key words: Salmonella, meningitis, neonates, chloramphenicol, Sri Lanka)

\section{Introduction}

Neonatal meningitis due to salmonella typhi is a relatively rare entity ${ }^{1}$. However, several cases had been reported in developing countries ${ }^{2}$. Here we present a case of neonatal meningitis due to salmonella typhi infection.

\section{Case report}

A 14 day-old baby boy presented to a district general hospital with fever and poor feeding of 4 days duration. In addition to fever, he did not have any other symptoms. He was the $3^{\text {rd }}$ baby born to nonconsanguineous healthy parents. He was born at term gestation with a birth weight of $3.5 \mathrm{~kg}$. There were no risk factors for sepsis in his antenatal or perinatal periods. Following admission, he developed a convulsion which lasted for 2 minutes. Examination revealed a bulging non-pulsatile anterior fontanelle and the head circumference (OFC) was $38 \mathrm{~cm}$. Rest of his neurological examination showed preserved primitive reflexes with no focal neurological signs.

Based on the clinical presentation, he was commenced on intravenous (IV) cefotaxime and ampicillin and lumbar puncture (LP) was performed later. His full blood count (FBC) was normal and the C-reactive protein (CRP) was $95 \mathrm{mg} / \mathrm{dl}$. LP on the $3^{\text {rd }}$ day of admission revealed 260 neutrophils, 215 lymphocytes and $145 \mathrm{mg} / \mathrm{dl}$ of proteins with a significant sugar difference (Table 1).

His blood, urine and cerebrospinal fluid (CSF) cultures were sterile. Due to poor clinical response, antibiotics were changed to IV meropenem for which he responded. IV antibiotics were given for a total of 21 days and the baby was discharged on day 35 .

Table 1: Summary of investigations

\begin{tabular}{|l|c|c|c|c|}
\hline \multicolumn{1}{|c|}{ Investigation } & Day 14 & Day 17 & Day 38 & Day 66 \\
\hline White blood cell count (per cu mm) & 8,500 & & 2,200 & 7,800 \\
\hline Haemoglobin level (g/dl) & 12.5 & & 11.8 & 8.9 \\
\hline Platelet count (per cu mm) & 34,900 & & 285,000 & 64,500 \\
\hline C-reactive protein (mg/dl) & 95 & & 221 & $<5$ \\
\hline Cerebrospinal fluid (CSF) protein & & 145 & 139 & 95 \\
\hline CSF sugar: blood sugar (mg/dl) & & $14: 77$ & $15: 52$ & $34: 75$ \\
\hline CSF neutrophils & & 260 & 60 & 03 \\
\hline CSF lymphocytes & & 215 & 140 & 18 \\
\hline CSF red blood cells & & 01 & 400 & 1300 \\
\hline
\end{tabular}

${ }^{1}$ Faculty of Medicine, University of Ruhuna, Sri Lanka, ${ }^{2}$ Teaching Hospital Karapitiya, Sri Lanka,

*Correspondence: imalke462@gmail.com iD, orcid.org/ 0000-0002-9351-2966

(Received on 06 February 2018: Accepted after revision on 16 March 2018)

The authors declare that there are no conflicts of interest

Personal funding was used for the project.

Open Access Article published under the Creative

Commons Attribution CC-BY (CC)
Three days following discharge ( $38^{\text {th }}$ day of life), he presented again with fever and a convulsion to Teaching Hospital Karapitiya. On admission, he was ill, less active and had a bulging anterior fontanelle. He was started on IV meropenem and repeat LP was done on the following day which was in favour of meningitis (Table 1). During the second admission his CRP was $229 \mathrm{mg} / \mathrm{dl}$ and the $\mathrm{FBC}$ revealed isolated neutropenia. The baby continued to have fever despite being on IV antibiotics. Contrast enhanced computed tomography (CECT) of the brain showed widespread hypodensities in bilateral white matter suggestive of diffuse cerebritis. (Figure 1). 


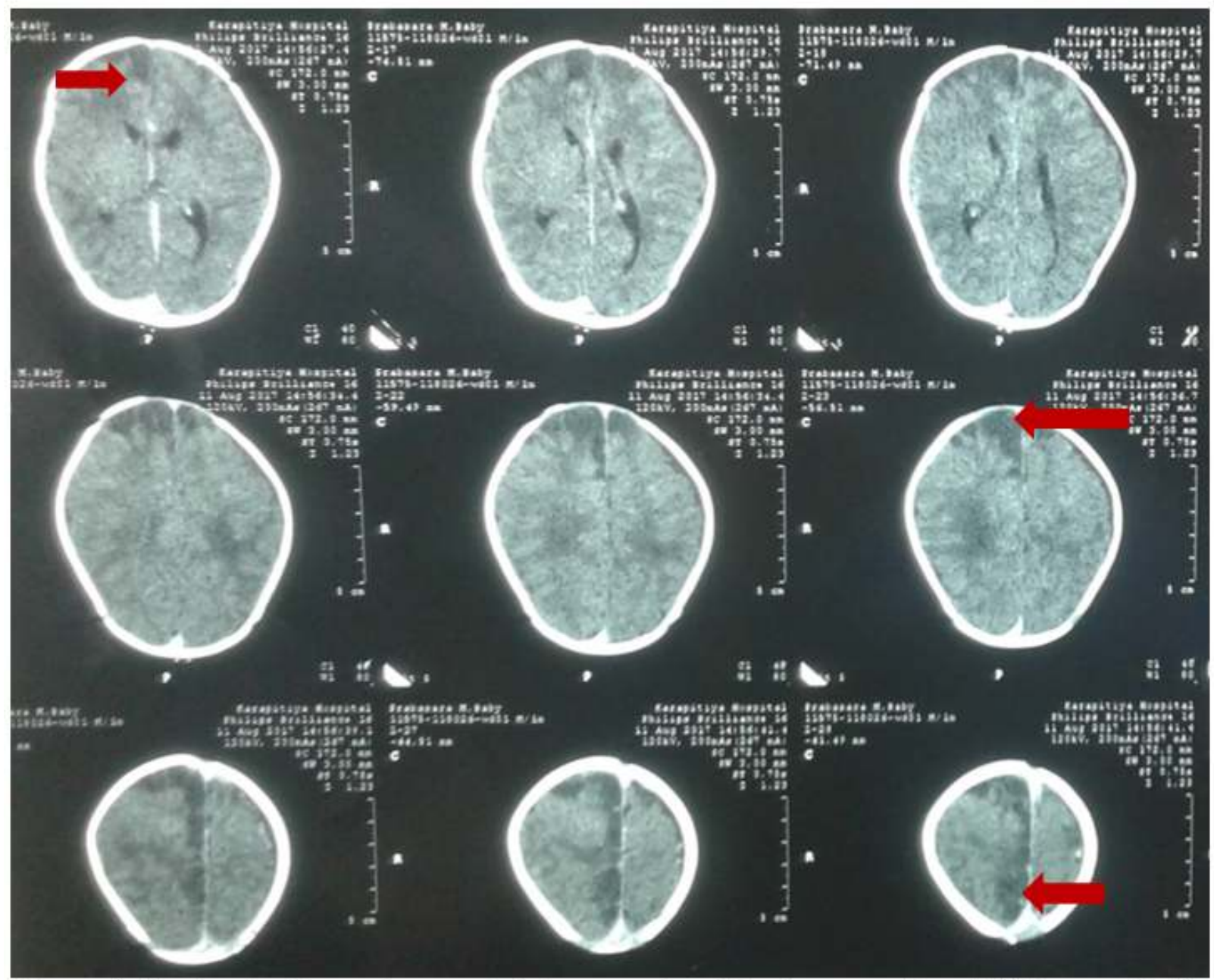

Figure 1: Contrast enhanced computed tomography of brain suggestive of diffuse cerebritis

His blood culture, which was done on day 38 , became positive for salmonella typhi and it was sensitive to meropenem and chloramphenicol. However, CSF culture and stool culture did not show any bacterial growth. Since there was no clinical improvement with IV meropenem, IV chloramphenicol was added and continued for 14 days for which he made a remarkable improvement. His standard agglutination test (SAT) was negative on two occasions and his subsequent basic hematological parameters and CSF findings became normal (Table 1). Maternal stools culture became negative for salmonella and no other family member was found to have salmonella carrier stage. Screening for salmonella infection was done among household contacts and was negative. He made an uneventful recovery. Follow up assessment at the age of four months revealed no developmental concerns or features of hydrocephalus. His hearing and visual assessments were normal.

\section{Discussion}

Typhoid fever is caused by faeco-oral transmission of salmonella typhi or salmonella paratyphi bacteria $^{3}$. The incidence of central nervous system (CNS) infections due to salmonella typhi varies between $3-35 \%{ }^{3}$. Meningitis secondary to salmonella is more common in the paediatric age group especially under 2 years of age ${ }^{1}$. Though salmonella meningitis is rare in neonates, it results in both short term as well as long term neurological sequelae such as seizures, subdural empyema, cerebritis, vetriculitis and hydrocephalus. In this patient, though neonatal seizures and radiological findings of diffuse cerebritis were evident, there were no long term adverse neurological complications.

The diagnosis of salmonella infection requires confirmation of the organism in blood, stool and urine. However, there are reported cases of salmonella meningitis where the organism had not been isolated in CSF but it was detected in blood ${ }^{5}$. In this baby, though CSF culture was negative, there were CSF changes suggestive of bacterial meningitis and blood culture became positive for salmonella typhi. In this case, the diagnosis was delayed due to negative blood culture during the first 
admission. However, repeat CSF examination would have revealed an ongoing infection, since $22 \%$ of neonatal meningitis cases had positive CSF even after completion of 21 days of antibiotics irrespective of the aetilogy $y^{6}$. Therefore, in such a circumstance the neonate should be reinvestigated and treated with a prolonged course of antibiotics.

Since salmonella is an intracellular organism, drug resistance is common among salmonella species which would aggravate the spreading of the organism. The recommended therapy for salmonella infection is IV third generation cephalosporins such as ceftriaxone for 4 weeks ${ }^{6}$. However, in this case, the organism was resistant to cephalosporins and responded only to IV chloramphenicol. Despite being on antibiotics, relapses are common in neonates with salmonella meningitis ${ }^{4}$. However, this baby made an uneventful long term recovery.

\section{References}

1. Rodriguez RE, Valero V, Watanakunakorn C. Salmonella focal intracranial infections: A review of the world literature (18841984) and the report of an unusual case. Reviews of Infectious Diseases 1986; 8:3141.

https://doi.org/10.1093/clinids/8.1.31

PMid: 3513285

2. Singhal V, Saleem EK, Rajesh SM, Coutinho A. Neonatal salmonella typhi meningitis: a rare entity. Journal of Clinical and Diagnostic Research 2012; 6(8):1433. https://doi.org/10.7860/JCDR/2012/4305. 2380
3. Huang DB, Du Pont H. Problem pathogens: extra-intestinal complications of Salmonella enterica serotype Typhi infection. Lancet Infectious Diseases 2005; 5: $341-8$. https://doi.org/10.1016/S14733099(05)70 138-9

4. West SE, Goodkin R, Kaplan A. Neonatal salmonella meningitis which was complicated by cerebral abscesses. Western Journal of Medicine 1977; 127:142-5.

PMid: 898945 PMCid: PMC1237737

5. Emejuru O, Jayam-Trouth A. Salmonella meningitis in infancy. Journal of the National Medical Association 1988; 80(7):824.

PMid: 3043006 PMCid: PMC2625794

6. Price EH, de Louvois J, Workman MR. Antibiotics for Salmonella meningitis in children. Journal of Antimicrobial Chemotherapy 2000; 46(5):653-5. https://doi.org/10.1093/jac/46.5.653 PMid: 11062183 